\title{
Assessment of innate immunity by phagocytic activity in non-descript and Sahiwal cattle in Chhattisgarh
}

\author{
Govina Dewangan¹, S. D. Hirpurkar¹, Devesh Kumar Giri² and Deepak Kumar Kashyap³
}

\begin{abstract}
1. Department of Veterinary Microbiology, College of Veterinary Science and Animal Husbandry, Durg, Chhattisgarh, India; 2. Department of Veterinary Pathology, Uttar Pradesh, Pandit Deen Dayal Upadhyaya Pashu Chikitsa Vigyan Vishwavidyalaya Evan Go Anusandhan Sansthan, Mathura, Uttar Pradesh, India; 3. Department of Veterinary Surgery and Radiology, College of Veterinary Science and Animal Husbandry, Arawali Veterinary College, Sikar, Rajasthan, India. Corresponding author: Govina Dewangan, e-mail: govinadewangan@gmail.com,

SDH: smpuhir@yahoo.com, DKG: giri.devesh18@gmail.com, DKK: deepakkashyap31@gmail.com Received: 26-07-2014, Revised: 05-10-2014, Accepted: 10-10-2014, Published online: 13-11-2014
\end{abstract}

Doi: 10.14202/vetworld.2014.943-947. How to cite this article: Dewangan G, Hirpurkar SD, Giri DK, Kashyap DK (2014) Assessment of innate immunity by phagocytic activity in non-descript and sahiwal cattle in Chhattisgarh, Veterinary World 7(11): 943-947.

\begin{abstract}
Aim: The objective of the research was to assess the innate immunity status of non-descript (ND) cattle in comparison to Sahiwal cattle in Chattisgarh by the determination of the phagocytosis activity (PA) and opsonocytophagic index (OI).

Materials and Methods: In-vitro phagocytic activity of neutrophil was studied in ND and Sahiwal (S) cattle after dividing them in groups viz. ND-I, ND-II, S-I and S-II. Neutrophils were separated from the blood and activated with Staphylococcus aureus. PA and OI were observed under high power of a microscope at $\times 1000$ magnification.
\end{abstract}

Results: PA (percent) in groups ND-I, ND-II, S-I and S-II was 73.00 $\pm 1.03,82.25 \pm 1.51,80.75 \pm 1.36$ and $82.37 \pm 1.27$, respectively which vary significantly $(\mathrm{p}<0.01)$, with respect to age. The observations regarding the OI (bacteria per neutrophil) in groups ND-I, ND-II, S-I and S-II was 7.17 $\pm 0.04,7.76 \pm 0.09,7.02 \pm 0.04$ and 7.79 \pm 0.06 , respectively. Age difference was evident, i.e., OI increases as age increases.

Conclusion: Innate immunity plays a vital role in host defense against diseases. Neutrophil kills the invading pathogen by phagocytic action. PA and OI is an important tool for the assessing innate immune status. After coincubation of neutrophil with bacterial cells, PA was significantly lower $(\mathrm{p}<0.01)$ in ND-I, calves group then other groups. Further, the result of OI clearly indicates that OI has increased as age increases in both breeds. The study will, therefore, generate first hand information on ND cattle along with their relative statistical differences, if any, when compared with Sahiwal.

Keywords: innate immunity, non-descript cattle, opsonocytophagic index, phagocytosis activity.

\section{Introduction}

Most of the cattle population in India is of non-descript (ND) types that is difficult to categories as any specific breed and hence broadly termed as indigenous local breed. While the research was conducted on production hike, the potential of indigenous breeds for disease resistance received less attention. India has 199 million cattle and 105.3 million buffalo population (9.49 million cattle and 1.6 million buffalo population present in Chhattisgarh [C.G.]) as per livestock census, [1]. Only $20 \%$ of these animals have been classified as recognized breeds and rest $80 \%$ is ND [2]. Major population of ND cattle remained undocumented although play an important role in the upliftment of small regional farmers [3].

In fact, ND and Sahiwal both are indigenous cattle breeds for C.G. later being a recognized breed. The Sahiwal is one such breed which is an established breed in C.G. and probably in whole India. Sahiwal is tick-resistant, heat-tolerant and noted for its high resistance to parasites, both internal and external [4]. In fact,

Copyright: The authors. This article is an open access article licensed under the terms of the Creative Commons Attributin License (http:// creative commons.org/licenses/by/2.0) which permits unrestricted use, distribution and reproduction in any medium, provided the work is properly cited. these unique characters are reflections of strong genetic make-up that govern innate immunity and its linage with adaptive/acquired immunity. Fortunately, in perspectives of C.G. State, Sahiwal can be considered as useful candidate animal for comparison with ND cattle about genetic and phenotypic capabilities are concerned.

Innate immunity in cattle varies between breeds and also with in breeds as per age, sex, strain, season, and more importantly the physiological status which decides its adaptability to the environment and available feed resources. Peak production potential of local cattle is less, but their relative cost of milk production is very low as compared to the dairy cattle reared in well developed dairy farming system [5]. Reduced production cost is attributed to the unique feature of their survival in the minimum quantities of feed and has innate potential to adapt to diverse climatic factors, diseases and susceptibility to parasites of geographic importance.

Innate immune system represents a highly conserved strategy against a wide array of bacterial, fungal, and viral pathogens. Activation of innate immune system results in an inflammatory response, which is essential to control infections rapidly before the infections spread to other parts of the body. It is now clear those cells of innate immune system contribute 
towards initiation and subsequently focus on ensuing adaptive immune responses [6]. Phagocytes are critical to the acute inflammatory response because they can efficiently engulf and destroy a variety of pathogens. Phagocytes comprised of neutrophils, monocytes, macrophages, and eosinophils, and they are also given the name of professional phagocytes. Phagocytosis of microorganisms is a key element in host defences against bacterial infections [7]. Phagocytic activity embraces the phagocytosis activity (PA) and opsonocytophagic index (OI) of neutrophils.

Neutrophils are classified as polymorphonuclear cells (PMN) which serve as the first line of cellular defense [8]. Rapid recruitment of sufficient numbers of PMN and increased phagocytosis in the beginning prevents establishment of any infection. Neutrophils exhibit a highly ruffled surface by exhibiting pseudopods on the surface. This increases the surface area of neutrophils and helps in augmenting phagocytosis by increasing the formation of phagosomes [9].

Although a lot of work has been done on milk and blood PMN, there is no such available information about ND cattle. The objective of the research was to assess the immunological status of ND cattle in comparison to Sahiwal cattle by the determination of the phagocytic activity.

\section{Materials and Methods}

\section{Ethical approval}

The M. V. Sc. research study was conducted after the approval of the Institutional Animal Ethics Committee, College of Veterinary Science and Animal Husbandry, Anjora, Durg.

\section{Selection of animals}

The study was planned to adjudge extent of innate immune response of village level local ND cattle and findings were compared with Sahiwal reared in an organized farm. ND cattle belonging to a Gaushala situated in Chhatagarh, Mohli, Durg (C.G.) and Sahiwal cows belonging to Bull Mother Experimental Farm, Anjora, Durg (C.G.) were selected to study innate immune response of local ND cattle and Sahiwal cows. 16 apparently and clinically healthy local ND cows (Group A), and 16 Sahiwal cows (Group B) were selected for study. The animals in each group were further divided into two subgroups viz. ND-I (6 months- 2 years age), ND-II (above 2 years), S-I (6 months-2 years age) and S-II (above 2 years) with eight animals in each subgroup. The animals were apparently free from ectoparasite infestation. The faecal sample examination for parasitic eggs did not reveal the presence of gastrointestinal parasites. All animals under study were also administered preventive dose of oral antiparasitic medicines as regular deworming programme. The animals were offered ad lib feed and fresh water at all the time of day.

\section{Blood sampling}

Blood samples were collected as per the protocols approved by the animal Ethics Committee of the
Institute. While collecting blood samples, adequate precautionary measures were taken to minimize pain and/or discomfort to the animals. $5 \mathrm{ml}$ of blood was collected aseptically by external jugular vein puncture from each cattle brought under the study in heparinized vails and used to perform phagocytic activity.

\section{Preparation of bacterial suspension}

Staphylococcus aureus was used to assess the phagocytic activity. Bacterial suspension was prepared as per the protocol followed by Samtani et al. [10]. Pure culture of $S$. aureus that maintained at department was used. $18 \mathrm{~h}$ old culture of $S$. aureus in nutrient broth was taken and centrifuged at $2000 \mathrm{rpm}$ for $10 \mathrm{~min}$, washed with physiological saline and opsonised at $37^{\circ} \mathrm{C}$ for $30 \mathrm{~min}$, with $10 \%$ pooled normal human serum. The suspension was again centrifuged at $2000 \mathrm{rpm}$ washed in PBS and diluted to give a final concentration of $2 \times 10^{8}$ bacteria $/ \mathrm{ml}$.

\section{I solation of blood PMN cells}

Isolation of PMN from peripheral blood was performed using hypotonic lysis of erythrocytes as described by Ordonez et al. [11] with slight modification. Blood was centrifuged at $1000 \mathrm{~g}$ for $20 \mathrm{~min}$ at $4^{\circ} \mathrm{C}$ in propylene conical tubes to obtained PMN cells. Plasma and buffy coat were discarded, but the compact pellet layer was preserved. From the pellet erythrocytes were lysed by addition of $4 \mathrm{ml}$ of blood to a sample tube containing $8 \mathrm{ml}$ of cold $4^{\circ} \mathrm{C}$ saline A solution $(\mathrm{NaCl}, 0.020 \mathrm{M}$ ), after $30 \mathrm{~s} 2 \mathrm{ml}$ of cold saline B solution ( $\mathrm{NaCl}, 0.164$ $\mathrm{M})$ were added to restore isotonicity. The lysate was centrifuged $3 \mathrm{~min}$ at $300 \mathrm{~g}$, and the recovered cell pellet was washed twice in Hank's balanced solution $(0.1 \%$ of bovine serum albumin $\mathrm{Ca}^{2+}$ and $\mathrm{Mg}^{2+}$ free). RPMI 1640 cell culture media supplement $(15 \% \mathrm{v} / \mathrm{v}$ fetal calf serum inactivated at $56^{\circ} \mathrm{C}$, penicillin $100 \mathrm{UI} / \mathrm{ml}$, streptomycin $100 \mu \mathrm{g} / \mathrm{ml}$,) was used for resuspension of pellet. PMN package was adjusted to $5 \times 10^{6}$ viable cells/ml. Viability checked by mixing $100 \mu \mathrm{l}$ of pellet and $0.4 \%$ try pan blue solution which reveal over $90 \%$ viable cells.

\section{Procedure of in vitro phagocytic activity}

The PA and OI were estimated by the method given by Malik [12] with slight modification as suggested by Ordonez et al. [11]. In vitro phagocytosis assay was performed by mixing $0.2 \mathrm{ml}$ of bacterial suspension and $0.2 \mathrm{ml}$ neutrophil suspension in the ratio of 40:1 (bacteria:neutrophil) in polyethylene microtubes and incubated at $37^{\circ} \mathrm{C}$ for $30 \mathrm{~min}$. Smears were prepared and stained with Leishman stain. Then slides were examined under high power microscope at $\times 1000$ magnification (Trinocular, H600L, DS Fi1-Nikon Eclipse50i, Japan).

a. PA (phagocytosis percentage) was estimated as a percentage of cells taking part in phagocytosis

$$
\begin{aligned}
& \text { Number of PMN } \\
& \text { that have engulfed }
\end{aligned}
$$

$$
\begin{aligned}
& \text { Phagocytosis } \\
& \text { activity }
\end{aligned}=\frac{\text { bacteria }}{\begin{array}{c}
\text { Number of } \\
\text { PMN counted }
\end{array}} \times 100
$$


b. OI was estimated as the mean amount of bacteria phagocytosed per the neutrophil.

Total bacteria in

Opsonocytophagic index $(\mathrm{OI})=\frac{\mathrm{N} \text { neutrophil }}{\mathrm{N}}$

Here, $\mathrm{N}=25$.

The result of PA was reported as percent (\%) phagocytosing neutrophils counting 100 PMN cells in different microscope fields and the result of OI was reported as average number of bacteria per neutrophil (bacteria per neutrophil).

\section{Statistical analysis}

The data were analyzed statistically by independent mean t-test to see the effect of age within a breed, if any, and to see the effect of breeds within the same age group, if any, following the standard procedure as outlined by Snedecor and Cochran [13].

\section{Results}

The purpose of the present study was to compare local ND cows with Sahiwal with respect to an important immune parameter that is phagocytic activity of PMN cells. The study will, therefore, generate first hand information on ND cattle along with their relative statistical differences, if any, when compared with Sahiwal.

\section{PA (phagocytosis percentage)}

The co-incubation of bacterial cells with neutrophils results in phagocytosis of bacteria. Percentage phagocytosis was calculated by noting the number of PMN that had engulfed bacteria, and a 100 PMN were counted. The result of PA is reported as percent and shown in Table-1 and Figure-1. PA was significantly low $(p<0.01)$ in ND calves with the values $73.00 \pm 1.03$. Another group of animal viz. ND-II, S-I and S-II had $\mathrm{PA}$ values rendered as $82.25 \pm 1.51,80.75 \pm 1.36$ and $82.37 \pm 1.2$, respectively.

\section{Ol (bacteria per neutrophil)}

The observations regarding the OI are shown in Table- 1 and Figures- 2 and 3. The analyzed data clearly indicate that OI has increased as age increases. The OI of ND calves was $7.17 \pm 0.04$ which increased to $7.76 \pm 0.09$ in adult group. Sahiwal group of animals showed a similar trend of increasing OI value with age, i.e., 7.02 \pm 0.04 in S-I and7.79 \pm 0.06 in S-II.

\section{Discussion}

In this study, there is a comparison of phagocytic activity between ND and Sahiwal based on breed and age specificity. A handful work had been carried out on different breed of well known significance at different physiological stages and different clinical condition, where as there was no information regarding phagocytic activity of local ND cattle. Blood neutrophils can be used as an efficient measure to assess the

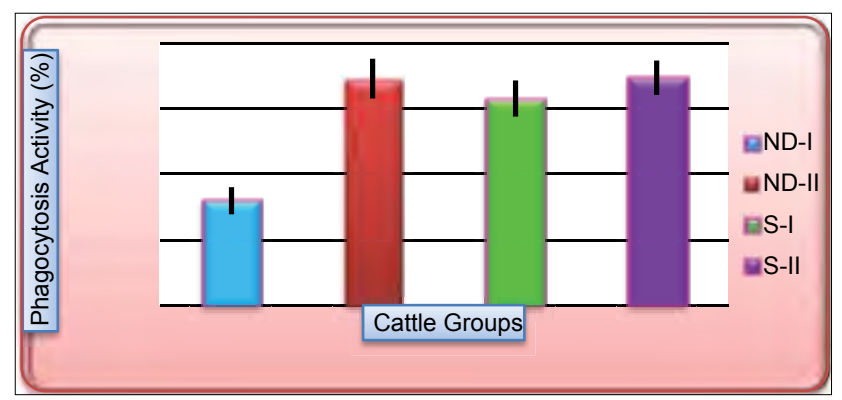

Figure-1: Mean ( \pm standard error) values of phagocytosis activity of non-descript (ND) and Sahiwal cattle, ND-I: ND cattle (6 months- 2 years age), ND-II: ND cattle (above 2 years age), S-I: Sahiwal cattle ( 6 months- 2 years age), S-II: Sahiwal cattle (above 2 years age).

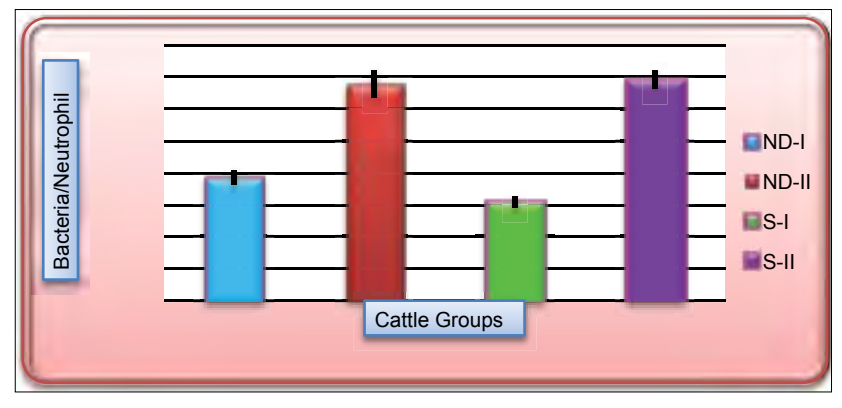

Figure-2: Mean ( \pm standard error) values of opsonocytophagic index bacteria/neutrophil of non-descript (ND) and Sahiwal cattle. ND-I: ND cattle ( 6 months 2 years age), ND-II: ND cattle (above 2 years age), S-I: Sahiwal cattle (6 months 2 years age), S-II: Sahiwal cattle (above 2 years age).

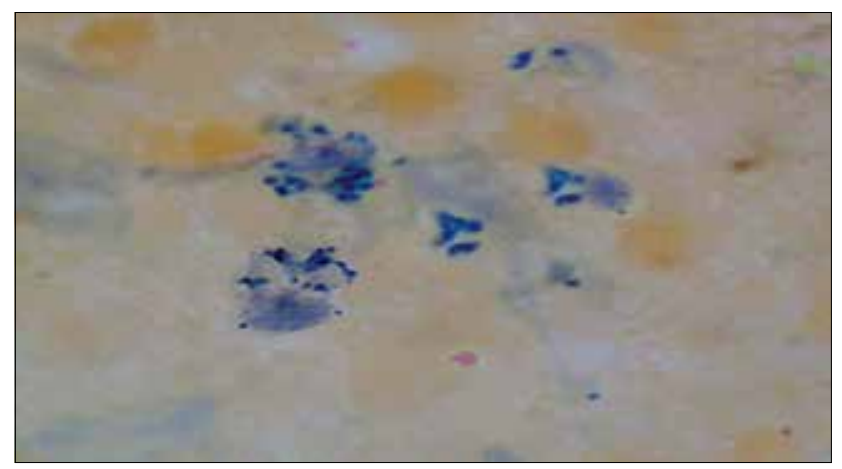

Figure-3: Bacteria phagocytosed by neutrophil showing opsonocytophagic index ( $\times 1000$ magnification; leishman stain).

Table-1: Phagocytosis in ND and Sahiwal cattle according to breed and age.

\begin{tabular}{|c|c|c|c|c|c|}
\hline \multirow[t]{2}{*}{ Group } & \multicolumn{2}{|c|}{ ND } & \multicolumn{2}{|c|}{ Sahiwal (S) } & \multirow{2}{*}{$\begin{array}{c}\text { Level of } \\
\text { significance }\end{array}$} \\
\hline & ND-I & ND-I I & S-I & S-II & \\
\hline PA (\%) & $73.00 \pm 1.03^{\mathrm{b}^{* *}}$ & $82.25 \pm 1.51^{a}$ & $80.75 \pm 1.36^{a}$ & $82.37 \pm 1.27^{a}$ & $* *$ \\
\hline Ol (bacteria/neutrophil) & $7.17 \pm 0.04^{b}$ & $7.76 \pm 0.09^{a}$ & $7.02 \pm 0.04^{b}$ & $7.79 \pm 0.06^{a}$ & $* *$ \\
\hline
\end{tabular}

$a, b, * *$ Highly significant at $1 \%$ level $(p<0.01)$, *Significant at $5 \%$ level $(p<0.05)$. Ol=Opsonocytophagic index, $\mathrm{PA}=$ Phagocytosis activity, ND=Non-descript 
innate immunity of cattle. The estimation of in-vitro activity of neutrophils in cattle can be effectively used for studying natural resistance [14]. They have reported that this technique can be further exploited to study the effect of antioxidants or specific drugs on neutrophils that may help to boost immunity in animals without having to affect their health. In present study PA of adult ND and Sahiwal cattle was more than that reported by Vishnoi et al. [14] who found 73 PA in netrophils for yeast cells from blood of Murrah buffaloes with clinical mastitis. Other workers found 100 PA while incubating whole blood with yeast cells [15]. Present in-vitro studies of PA of neutrophils were in agreement to the report of Dosogne et al. [16] when neutrophils were incubated with $S$. aureus, blood PMN phagocytosed about $82 \%$ S. aureus and found no significant difference between different stages of lactation.

Many diseases can affect numbers of white blood cells (leukocytes) in peripheral blood, and several assays are available to determine total leukocyte number. Traditionally, peripheral blood mononuclear cells are separated from red blood cells using density-gradient centrifugation [17]. Neutrophils (PMN leukocytes) are important members of professional phagocytes. They are most numerous in circulation, and these are usually the first cells to arrive at the site of inflammation. It is possibly the most significant cellular component of the innate response during an acute infection [18]. Weak phagocytosis is better detected by phagocytosis percentage, and high PA is best shown by calculating phagocytosis index [19]. Further, the surface architecture demonstrated by scanning electron microscope provides insight for activity of phagocytic cells. Diminished phagocytic activity of milk neutrophils revealed a smooth membrane of milk neutrophils where as blood neutrophils exhibited more ruffled membrane and enhanced phagocytic activity [8]. To predict the resistance and susceptibility of animal depending on the PA and OI; concentration of neutrophils, various parameters such as activation state of PMN, their intrinsic bactericidal activity, the presence of antibodies opsonizing the bacteria and neutralizing their toxins have to be taken into account [20]. Ordonez et al. [11] assessed the in-vitro differential neutrophil PA on $S$. aureus obtained from blood and milk of Holstein dairy cows in early lactation period and observed a greater in-vitro mean PA $(86.5 \pm 9.6 \%)$ and phagocytosis index $(7.34 \pm 1.55)$ in blood PMN neutrophil cells in comparison to milk cells. They concluded that PMN cells obtained by erythrocyte lysis and lypopolysaccharide udder stimulation are useful for in-vitro reproducible phagocytosis assay.

\section{Conclusion}

The result of the present study indicated that although, the PA and OI were less in ND animals of below 2 years of age there was a significant increase up to 2 years of age. Resultant optimal levels attained are similar to with those of Sahiwal calves as well as adult animals. PA and OI in ND calves attained optimal levels at par with those of Sahiwal animals. This shows that the gain in natural resistance of ND animal though appear slow in early age, they make-up their innate immune status as age advances.

\section{Authors' Contributions}

GD and SDH planned and designed the experimental study. GD performed the study under the supervision and technical support of SDH. GD, DKK and DKG performed the collection and processing of the sample. GD, DKG and DKK drafted and reviewed the manuscript. All authors read and approved the final manuscript.

\section{Acknowledgments}

The authors are thankful to the Dean, College of Veterinary Science and Animal Husbandry, Anjora, Durg for providing university funds (IGAU,Raipur) and all the required facilities to carry out the research.

\section{Competing I nterests}

The authors declare that they have no competing interests.

\section{References}

1. Chhattisgarh Government Livestock Census. (2007) Districtwise details of livestock census. Available from: http://www.ahd.cg.gov.in. Last accessed on 24-09-2014.

2. Tomar, S.S. (2010). Textbook of Animal Breeding. Kalyani Publishers, New Delhi, India.

3. Nqeno, N. (2008) Reproductive performance of cows in sweet and sour field types under communal production systems in Eastern Cape Province of South Africa. Master of Science in Animal Science Thesis Submitted to University of Fort Hare.

4. Nivsarkar, A.E., Vij, P.K. and Tantia, M.S. (2000) Animal Genetic Resources of India Cattle and Buffalo. Vinayak Press, New Delhi, India.

5. Chande, R.S.S. (2011) Characterization of local cows of northern hilly region of Chhattisgarh. M. V. Sc. Thesis Submitted to Indira Gandhi Krishi Vishwavidyalaya, Raipur (C.G.).

6. Janeway, J. and Medzhitov, R. (2002) Innate immune recognition, Annu. Rev. Immunol., 20: 197-116.

7. Kantari, C., Pederzoli, M. and Witko S.V. (2008) The role of neutrophils and monocytes in innate immunity. Contrib. Microbiol., 15: 118-146.

8. Mohapatra, A., Swain, D.K., Pathan, M.M.K., Kaur, M. Panigrahy, S.R., Kapila, S., Kapila, R., Prasad, S., Mohanty, A.K. and Dang, A.K. (2012) Scanning electron microscopy and phagocytic activity of blood and milk neutrophils isolated from early lactating buffaloes. Indian J. Dairy Sci., 65(6): 479-483.

9. Mehrzad, J., Duchateau, L. and Burvenich, C. (2004) Viability of milk neutrophils and severity of bovine coliform mastitis. J. Dairy Sci., 87: 4150-4162.

10. Samtani, J.R., Wagle, S.U., Irani, S.F. and Kshirsagar, N.A. (1991) Micromethod for PMN function studies in neonates. J. Postgrad. Med., 37: 160.

11. Ordonez, V.V., Salas, N.P., Gorodezky, C. and Oaxaca, J.S. (2008) In-vitro differential neutrophil phagocytosis activity on Staphylococcus aureus when obtained from blood and milk of dairy cows in early lactation period. Rev. Latinoam. Microbiol., 50: 66-71. 
12. Malik, B.S. (1986) A Laboratory Manual of Bacteriology, Mycology \& Immunology. CBS Publishers and Distributors, Delhi.

13. Snedecor, G.W. and Cochran, W.G. (1994) Statistical Methods. $8^{\text {th }}$ ed. Iowa State University Press Ames, Iowa, USA.

14. Vishnoi, P.C., Dang, A.K. and Kapila, S. (2007) In vitro phagocytic activity of neutrophils isolated from blood, milk of Murrah buffaloes with clinical mastitis. Buffalo J., 1: 51-59.

15. Guidry, A.J., Pappe, M.J. and Miller, R.H. (1974) In vitro procedure for measuring phagocytosis of blood neutrophils. Am. J. Vet. Res., 35: 705-709.

16. Dosogne, H., Vangroenweghe, F., Barrio, B., Rainard, P. and Burvenich, C. (2001) Decreased number and bactericidal activity against staphylococcus aureus of the resident cells in milk of dairy cows during early lactation. J. Dairy Res., 68: 539-549.

17. Windsor, M. (2012) A simple no-wash method for the flow cytometric enumeration of leukocyte subsets in whole blood. Excerpt MACS More., 14: 26-29.

18. Choi, E.Y., Santoso, S. and Chavakis, T. (2009) Mechanisms of neutrophil transendothelial migration, Front Biosci., 14: 1596-1605.

19. Kassinen, S.S. (1986) Optimal conditions for the opsonophagocytosis test with streptococcus pneumonia serotypes 3, 6A, 7F and 19F and human granulocytes. Acta Pathol. Microbiol. Immunol. Scand., 94(3): 105-111.

20. Rainard, P. and Riollet, C. (2003) Mobilization of neutrophils and defense of bovine mammary gland. Reprod. Nutr. Dev., 43: 439-457.

$* * * * * * * *$ 